\title{
Sliding-mode controller for a step up-down battery charger with a single current sensor
}

\author{
Juan Pablo Villegas-Ceballos ${ }^{1}$, Carlos Andrés Ramos-Paja ${ }^{2}$, Elkin Edilberto Henao-Bravo ${ }^{3}$ \\ ${ }^{1}$ Departamento de Electrónica y Telecomunicaciones, Instituto Tecnológico Metropolitano, Medellín, Colombia \\ ${ }^{2}$ Facultad de Minas, Universidad Nacional de Colombia, Medellín, Colombia \\ ${ }^{3}$ Departamento de Mecatrónica y Electromecánica, Instituto Tecnológico Metropolitano, Medellín, Colombia
}

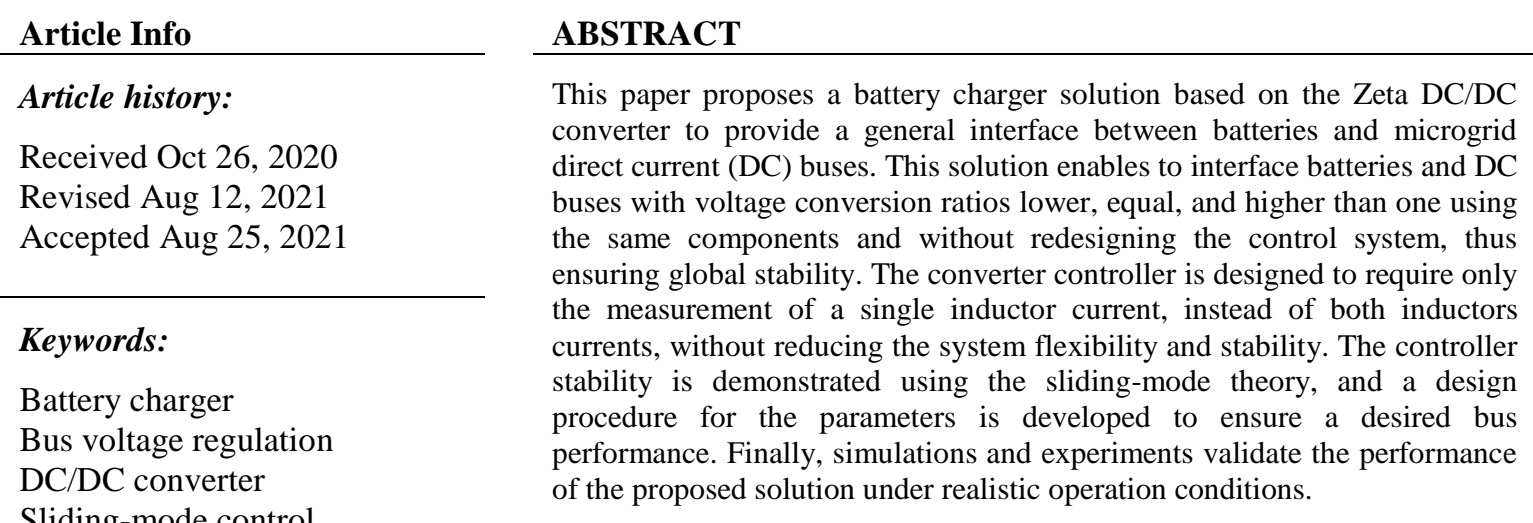

This is an open access article under the CC BY-SA license.

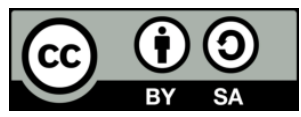

Corresponding Author:

Juan Pablo Villegas-Ceballos

Departamento de Electrónica y Telecomunicaciones, Instituto Tecnológico Metropolitano-ITM

Calle 73 No. 76A-354, Vía al Volador, Medellín 050034, Colombia

Email: juanvillegas@itm.edu.co

\section{INTRODUCTION}

Direct curent (DC) microgrids are one of the most adopted structures to distribute power generated with renewable energy sources [1], [2]. Those microgrids require energy storage devices, usually batteries, to store energy when the sources production is higher than the load consumption; similarly, the batteries provide energy when the load consumption is higher than the sources production [3], [4]. Moreover, DC microgrids have a common bus in which both sources and loads are connected, hence the stability of such a bus is required to guarantee the safe operation of both sources and loads [1], [2]. Therefore, the batteries in DC microgrids can be interfaced using DC/DC converters, which are controlled to regulate the DC bus: When the sources produce higher power with respect to the load request, the bus voltage increases, hence the DC/DC converter must to charge the battery to ensure a regulated DC bus; similarly, when the requested load power is higher than the power produced by the sources, the bus voltage decreases and the DC/DC converter must to discharge the battery to ensure a regulated DC bus [5], [6]. In this way, the DC/DC converter ensures both the voltage stability and the power balance of the DC bus.

Battery chargers are formed by DC/DC converters and controllers. Those DC/DC converters must to support the voltage difference between the battery and the DC bus; therefore, the battery chargers are designed with step-down topologies when the battery voltage is lower than DC bus voltage [7]-[9]. Similarly, step-up converters are used to design battery chargers to interface a DC bus with a higher voltage battery bank [2], [10]-[12]. In addition, buck-boost topologies have been used to interface DC buses and battery banks with similar voltages [13]-[16]. Concerning the controllers, battery chargers require control 
systems to ensure the stability of the DC bus in any operation condition. One example of those controllers is shown in [2], which proposes a two-layers controller with the primary layer based on an adaptive voltage regulator. Similarly, Fakham et al. [17] presented a voltage regulation for the connection of the battery to a microgrid using an inner current controller, and such a control structure is modified based on parameters of the microgrid such as the battery state of charge (SoC).

Another example can be found in charging stations for vehicles, where the charger is connected to the grid, and the high power required to charge the battery generates a power factor different from one and a high total distortion harmonics (THD) [18]. Therefore, Fakham et al. [17] was proposed a voltage control oriented (VOC) where the decomposition of direct and quadrature components allows to correct the power factor and avoid the total harmonic distortion, also controlling the DC voltage bus. Other non-linear controllers were proposed in the literature to provide a voltage regulation in battery chargers, such as fuzzy controllers [6], [19], [20] model predictive controllers (MPC) [21] and sliding mode controllers (SMC) [5], [15], [22]. In particular, the surface of the SMC used for battery chargers, based on high-order converters, frequently requires the measurement of two voltages and two currents to ensure bus stability in both charging and discharging modes, which is the case of the charger controller presented in [23]. Other control objectives that have been also proposed to regulate battery chargers are the SoC equalization, using a MPC [24] and SMC [25], the thermal balance in the battery pack [21], the battery state of health ( $\mathrm{SoH})$ using proportionalintegral-derivative (PID), feedback linearization and SMC [26], and the charge control within a safe region using constant current and constant voltage modes [27].

The previous literature review put into evidence that microgrid applications require the regulation of the DC bus voltage; for that purpose, battery charger-dischargers are used to interface battery banks with voltages higher, lower, or equal than the DC bus voltage. Hence, buck-boost type converters are the best option to adapt to different voltage levels. Although some solutions have been proposed to address this problem, it is important to reduce the number of sensed currents, which reduces the complexity and cost of the control system, but it must be ensured that the regulation and dynamic behavior of the DC bus is not affected [22].

To address the previous problem, this paper proposes a battery charger based on a Zeta converter, which is able to interface batteries with voltages lower, equal, or higher than the DC bus voltage. This characteristic enables the same battery charger to interface different battery banks independent of the voltage provided by the bank, which is an advantage over step-down or step-up only battery chargers, e.g. boost and buck based solutions [2], [7]-[11], [28]. Moreover, the Zeta converter has an inductor at the output port connected to the DC bus [6], [28]-[31], which makes possible to control the bus voltage with high precision and, at the same time, this enables the converter to provide a continuous current to the DC bus, reduces the harmonic components present in the microgrid; this is an advantage over battery chargers based on converters with discontinuous output current, e.g. buck and buck-boost based solutions [15], [32]-[34]. The proposed battery charger is regulated using sliding-mode theory, which provides robustness to changes on the electrical parameters and operation conditions [35]. The main objectives of the proposed controller are to ensure a stable bus voltage, and to avoid the measurement of both inductor currents. The first objective aims to provide a safe operation to the microgrid; while the second objective aims to simplify the controller implementation by requiring a single current sensor instead of two as it is done in other implementations [23], hence reducing system cost and improving reliability.

The paper is organized as follows: section 2 describes the proposed method, in which subsection 2.1 shows the battery charger circuit and provides a mathematical model to design the controller. Then, subsection 2.2 presents the controller and demonstrates the global stability using analytical proofs. Subsection 2.3 provides a design procedure for the controller parameters to ensure a desired performance of the bus voltage. Then, section 3 shows the results and discussion, where subsection 3.1 describes the controller implementation and evaluates the system performance using realistic circuital simulations. Subsection 3.2 uses a proof-of-concept prototype to provide experimental validation of the proposed solution. Finally, section 4 closes the paper with the conclusions of the work.

\section{PROPOSED METHOD}

\subsection{Battery charger circuit and model}

The battery charger is designed using a Zeta converter and a SMC measuring the first inductor current and the bus voltage. Figure 1 presents the electrical scheme of the battery charger, which is formed by two metal oxide semiconductor field effect transistors (MOSFETs) (M1 and M2), two inductors (L1 and L2), a differential capacitor $\left(\mathrm{C}_{\mathrm{d}}\right)$, the DC bus capacitor $\left(\mathrm{C}_{\mathrm{dc}}\right)$, and the controller (SMC). Such a SMC measures the bus voltage $\left(v_{d c}\right)$, the battery voltage $\left(v_{b}\right)$ and the L1 inductor current $\left(i_{L 1}\right)$ to produce the activation signals of both MOSFETs ( $u$ and $\overline{\mathrm{u}}$ ) that force $\mathrm{v}_{\mathrm{dc}}$ to be equal to the reference value $\mathrm{v}_{\mathrm{R}}$. Such a circuit is a bidirectional 
version of the Zeta converter, in which $\overline{\mathrm{u}}$ is the complementary signal of $\mathrm{u}(\overline{\mathrm{u}}=1-\mathrm{u})$. Moreover, this electrical scheme models the battery as an ideal voltage source; while the microgrid bus is modeled with the capacitor $\mathrm{C}_{\mathrm{dc}}$ and a current source $\left(\mathrm{i}_{\mathrm{dc}}\right)$, this is an accurate model since idc reproduces the difference between the current supplied by the sources and the current requested by the loads, while Cdc represents the sum of all the sources output capacitances and loads input capacitances.

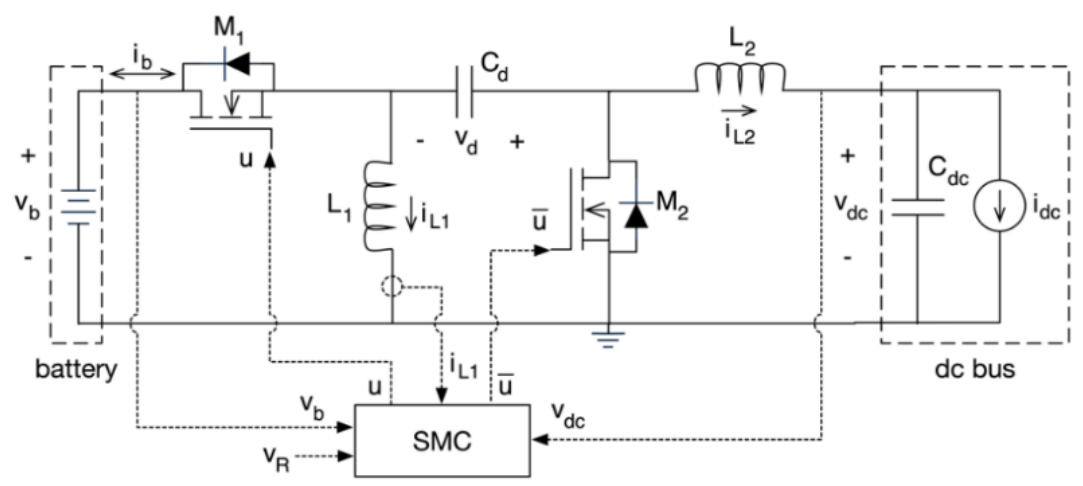

Figure 1. Electrical scheme of the battery charger

The previous scheme shows that the current reaching the DC bus is the L2 inductor current ( $\left.\mathrm{i}_{\mathrm{L} 2}\right)$, which is continuous. Moreover, L2 and $C_{d c}$ form a second order filter [36], which reduces even more the current harmonic content injected to the DC bus. This power converter is modeled using the switched differential equations of both inductor currents and both capacitor voltages:

$$
\begin{aligned}
& \frac{d i_{L 1}}{d t}=\frac{v_{b} \cdot u-v_{d} \cdot \bar{u}}{L_{1}} \\
& \frac{d i_{L 2}}{d t}=\frac{\left(v_{b}+v_{d}\right) \cdot u-v_{d c}}{L_{2}} \\
& \frac{d v_{d}}{d t}=\frac{i_{L 1} \cdot \bar{u}-i_{L 2} \cdot u}{C_{d}} \\
& \frac{d v_{d c}}{d t}=\frac{i_{L 2}-i_{d c}}{C_{d c}}
\end{aligned}
$$

In those equations $v_{d}$ is the voltage of the differential capacitor. The steady-state (and slow frequency variation) values of those currents and voltages are obtained by considering the derivatives equal to zero, which leads to (5) to (7), where $\mathrm{d}$ is the duty cycle of the converter calculated as given in (8) with $\mathrm{T}$ representing the switching period.

$$
\begin{aligned}
& \mathrm{i}_{\mathrm{L} 1}=\mathrm{i}_{\mathrm{L} 2} \cdot \frac{\mathrm{d}}{1-\mathrm{d}} \\
& \mathrm{i}_{\mathrm{L} 2}=\mathrm{i}_{\mathrm{dc}} \\
& \mathrm{v}_{\mathrm{dc}}=\mathrm{v}_{\mathrm{b}} \cdot \frac{\mathrm{d}}{1-\mathrm{d}}=\mathrm{v}_{\mathrm{d}} \\
& \mathrm{d}=\frac{1}{\mathrm{~T}} \int_{0}^{\mathrm{T}} \mathrm{udt}
\end{aligned}
$$

The previous equations describe the stable operation conditions of the Zeta converter. In particular, (5) defines the relation required between $i_{L 1}$ and $i_{L 2}$ to provide a stable operation of the converter. Similarly, 
(7) defines the value of $v_{d}$ required for the same stable operation. Finally, (5) to (7) are valid for frequencies below the switching frequency since those expressions depend on the duty cycle, which is the averaged value of the control signal $u$.

\subsection{Design and analysis of the sliding-mode controller}

The proposed SMC is based on the bus voltage and L1 current measurements to ensure a stable bus voltage equal to $v_{R}$, i.e., the microgrid reference voltage. Taking into account that the main objective of the SMC is to regulate the bus voltage $v_{\mathrm{dc}}$, the controller considers the error between $\mathrm{v}_{\mathrm{dc}}$ and $\mathrm{v}_{\mathrm{R}}$, and the integral of such a component is also considered to ensure a null steady-state error. In addition, since the current in inductor L2 must fulfill (5) for a stable operation, then the changes on the bus voltage $\mathrm{v}_{\mathrm{dc}}$, caused by $\mathrm{i}_{\mathrm{L} 2}$, are also consequence of changes on $i_{\mathrm{L} 1}$. This solution considers measuring $\mathrm{i}_{\mathrm{L} 1}$ instead of $\mathrm{i}_{\mathrm{L} 2}$ since $\mathrm{L} 1$ is connected to ground, which significantly simplifies the current measurements and signal conditioning. Instead, the terminals of L2 are floating, hence a current sensor for $\mathrm{i}_{\mathrm{L} 2}$ is much costly and the signal conditioning must consider differential circuits, which are difficult to isolate and will be subjected to larger voltages in comparison with the single voltage circuits required to measure $i_{\mathrm{L} 1}$. Finally, the switching function defined to develop the SMC is presented in (9), in which $\mathrm{X}, \mathrm{Y}$ and $\mathrm{Z}$ are constants. Moreover, the sliding surface imposed by the SMC is given in (10), i.e., force the switching function to be equal to zero.

$$
\begin{aligned}
& \Psi=X \cdot\left(v_{R}-v_{d c}\right)+Y \cdot \int\left(v_{R}-v_{d c}\right) d t+Z \cdot i_{L 1} \\
& \Phi=\{\Psi=0\}
\end{aligned}
$$

To ensure the stability of a sliding-mode controller three conditions must be fulfilled: transversality, reachability and equivalent control. The transversality condition verifies that the control signal $\mathrm{u}$ is present into the derivative of the switching function, which guarantee that the system trajectory can be controlled. The reachability conditions verify that the system is able to reach the sliding surface, hence it verifies that the switching function given in (9) is able to reach the condition defined in (10). Finally, the equivalent control condition verifies that the system continues operating inside the surface [3]. The following subsections analyze those conditions to verify the stability of the proposed SMC.

\subsubsection{Transversality condition}

The formalization of the transversality condition is given in (11), which requires the explicit expression of the switching function derivate for the analysis. Therefore, (12) presents the derivative of the switching function given in (9) and replacing (1) and (4) into (11), leads to the explicit expression given in (13). Such an expression takes into account that microgrids usually require a constant bus voltage to provide safe and stable operation conditions to both sources and loads [1], [2], therefore the reference value $v_{R}$ is constant, i.e. $\frac{\mathrm{d} v_{\mathrm{R}}}{\mathrm{dt}}=0$.

$$
\begin{aligned}
& \frac{\mathrm{d}}{\mathrm{du}}\left(\frac{\mathrm{d} \Psi}{\mathrm{dt}}\right) \neq 0 \\
& \frac{\mathrm{d} \Psi}{\mathrm{dt}}=-\mathrm{X} \cdot \frac{\mathrm{d} \mathrm{v_{ \textrm {dc } }}}{\mathrm{dt}}+\mathrm{Y} \cdot\left(\mathrm{v}_{\mathrm{R}}-\mathrm{v}_{\mathrm{dc}}\right)+\mathrm{Z} \cdot \frac{\mathrm{d} \mathrm{i}_{\mathrm{L} 1}}{\mathrm{dt}} \\
& \frac{\mathrm{d} \Psi}{\mathrm{dt}}=-\mathrm{X} \cdot\left(\frac{\mathrm{i}_{\mathrm{L} 2}-\mathrm{i}_{\mathrm{dc}}}{\mathrm{C}_{\mathrm{dc}}}\right)+\mathrm{Y} \cdot\left(\mathrm{v}_{\mathrm{R}}-\mathrm{v}_{\mathrm{dc}}\right)+\mathrm{Z} \cdot\left(\frac{\mathrm{v}_{\mathrm{b}} \cdot \mathrm{u}-\mathrm{v}_{\mathrm{d}} \cdot \overline{\mathrm{u}}}{\mathrm{L}_{1}}\right)
\end{aligned}
$$

Finally, evaluation (11) using (13):

$$
\frac{\mathrm{d}}{\mathrm{du}}\left(\frac{\mathrm{d} \Psi}{\mathrm{dt}}\right)=\frac{\mathrm{Z}}{\mathrm{L}_{1}} \cdot\left(\mathrm{v}_{\mathrm{b}}+\mathrm{v}_{\mathrm{d}}\right) \neq 0
$$

In such an expression $\mathrm{L} 1$ and $\mathrm{v}_{\mathrm{b}}$ are values different than zero. Moreover, according to (7), the averaged values of $v_{d}$ and $v_{d c}$ are equal, hence vd must be also different from zero. Finally, $\mathrm{Z}$ must be also different from zero to include the measurement of $i_{L 1}$ into the SMC; therefore (14) is different from zero and it confirms that the transversality condition is fulfilled. It must be noted that $\mathrm{L} 1, \mathrm{v}_{\mathrm{b}}$ and $\mathrm{v}_{\mathrm{d}}$ are positive quantities, therefore the sign of the transversality condition (14) depends on the sign of $\mathrm{Z}$. 


\subsubsection{Reachability conditions}

The reachability conditions are formalized as follows: if the switching function is operating over the surface $(\Psi>0)$, then the switching function derivative must be negative $\left(\frac{\mathrm{d} \Psi}{\mathrm{dt}}<0\right)$ to reach the surface $(\Psi=0)$; similarly, if the switching function is operating under the surface $(\Psi<0)$, then the switching function derivative must be positive $\left(\frac{\mathrm{d} \Psi}{\mathrm{dt}}>0\right)$ to reach the surface $(\Psi=0)$. In addition, (11) also provides information concerning the behavior of the switching function derivative for changes on the control variable $\mathrm{u}$ : a positive sing of (11) implies that positive changes on $\mathrm{u}$ (from 0 to 1 ) produce a positive value of $\frac{\mathrm{d} \Psi}{\mathrm{dt}}$; similarly, a negative sing of (11) implies that the same positive change on $u$ produces a negative value of $\frac{d \Psi}{d t}$. Therefore, a positive transversality sing requires $\mathrm{u}=1$ to impose a positive $\frac{\mathrm{d} \Psi}{\mathrm{dt}}$ value and $\mathrm{u}=0$ to impose a negative $\frac{\mathrm{d} \Psi}{\mathrm{dt}}$ value; instead, a negative transversality sing requires $u=0$ to impose a positive $\frac{d \Psi}{d t}$ value and $u=1$ to impose a negative $\frac{d \Psi}{d t}$ value. The visual representation of those conditions is presented in Figure 2, which considers both positive and negative transversality conditions.

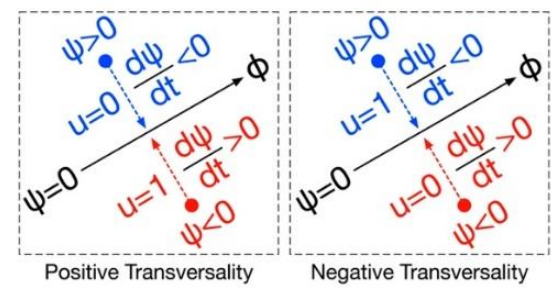

Figure 2. Impact of the transversality sing on the reachability conditions

The sign of the transversality condition for the proposed SMC, analyzed from (14), depends on the sign of Z. Therefore, this work adopts a negative sign for $\mathrm{Z}$ due to the implementation simplicity of the negative transversality condition, but a slightly more complex circuit could be used to implement the positive transversality condition. Therefore, considering $\mathrm{Z}<0$ the SMC exhibits a negative transversality condition, and using the descriptions summarized in Figure 2, the following control law (15) and reachability conditions (16)-(17) are formalized:

$$
\begin{aligned}
& u=\left\{\begin{array}{l}
1 \text { if } \Psi>0 \\
0 \text { if } \Psi<0
\end{array}\right. \\
& \left.\lim _{\Psi \rightarrow 0^{-}} \frac{d \Psi}{d t}\right|_{u=0}>0 \\
& \left.\lim _{\Psi \rightarrow 0^{+}} \frac{d \Psi}{d t}\right|_{u=1}<0
\end{aligned}
$$

Replacing the value of the switching function derivative, reported in (13), into the first reachability condition (16) leads to (18). Under steady-state conditions $i_{L 2}=i_{d c}$ as it was demonstrated in (6), and the controller action ensures that the averaged value of $v_{d c}$ must be equal to $v_{R}$. Therefore, (18) is positive since $\mathrm{Z}<0, \mathrm{v}_{\mathrm{d}}>0$ and L1 $>0$, which fulfills the first reachability condition (16).

$$
\left.\lim _{\Psi \rightarrow 0^{-}} \frac{d \Psi}{d t}\right|_{u=0}=-X \cdot\left(\frac{i_{L 2}-i_{d c}}{C_{d c}}\right)+Y \cdot\left(v_{R}-v_{d c}\right)-Z \cdot\left(\frac{v_{d}}{L_{1}}\right)>0
$$

Similarly, replacing the value of the switching function derivative (13) into the second reachability condition (17) leads to (19). Since under steady-state conditions $i_{L 2}=i_{d c}$ and the averaged value of $v_{d c}$ is equal to $v_{R}$, then (19) is negative because $\mathrm{Z}<0, v_{b}>0$ and L1 $>0$, which fulfills the second reachability condition (17).

$$
\left.\lim _{\Psi \rightarrow 0^{+}} \frac{d \Psi}{d t}\right|_{u=1}=-X \cdot\left(\frac{i_{L 2}-i_{d c}}{C_{d c}}\right)+Y \cdot\left(v_{R}-v_{d c}\right)+Z \cdot\left(\frac{v_{b}}{L_{1}}\right)<0
$$




\subsubsection{Equivalent control condition}

The equivalent control condition verifies that the duty cycle of the converter is not saturated. As it was described in (8), the duty cycle corresponds to the averaged value of $u$, also named $u_{\text {eq }}$, which must fulfill the following physical restriction (20):

$$
0<\mathrm{u}_{\mathrm{eq}}=\mathrm{d}<1
$$

The equivalent control condition is analyzed into the surface, which corresponds to a trajectory $\Psi=0$ parallel to the surface, hence $\frac{\mathrm{d} \Psi}{\mathrm{dt}}=0$ [37]. Therefore, the value of the equivalent control signal $\mathrm{u}_{\mathrm{eq}}$ is obtained by making (13) equal to zero (21):

$$
\mathrm{u}_{\mathrm{eq}}=\left\{-\left[-\mathrm{X} \cdot\left(\frac{\mathrm{i}_{\mathrm{L} 2}-\mathrm{i}_{\mathrm{dc}}}{\mathrm{C}_{\mathrm{dc}}}\right)+\mathrm{Y} \cdot\left(\mathrm{v}_{\mathrm{R}}-\mathrm{v}_{\mathrm{dc}}\right)\right] \cdot \frac{\mathrm{L}_{1}}{\mathrm{Z}}+\mathrm{v}_{\mathrm{d}}\right\} \cdot\left(\frac{1}{\mathrm{v}_{\mathrm{d}}+\mathrm{v}_{\mathrm{b}}}\right)
$$

Replacing the previous $\mathrm{u}_{\mathrm{eq}}$ value into restriction (20) leads to the same inequalities (18) and (19) analyzed in the previous subsection 2.2.2. Therefore, the equivalent control condition is also fulfilled. This is expected since Sira-Ramirez demonstrated in [3] that any SMC designed for DC/DC converters fulfilling both transversality and reachability conditions also fulfills the equivalent control condition.

Finally, this subsection has demonstrated the stability of the SMC, based on (9) and (10), proposed to regulate the Zeta battery charger. However, the dynamic behavior of the bus voltage has not been defined. Therefore, the following section presents a procedure to design $\mathrm{X}, \mathrm{Y}$ and $\mathrm{Z}$ parameters to impose the desired performance to the microgrid bus.

\subsection{Design of the bus voltage behavior}

The Zeta converter, operating in closed-loop under the action of the proposed SMC, is stable as it was demonstrated in the previous section. Therefore, the relation between $i_{L 1}$ and $i_{L 2}$ reported in (5) is fulfilled. Moreover, the averaged current of the MOSFET M1 (within the switching period) is equal to $d \cdot i_{L 1}$ since that MOSFET is active during $\mathrm{d} \cdot \mathrm{T}$ seconds, and the averaged current of the MOSFET M2 (within the switching period) is equal to $d \cdot i_{\mathrm{L} 2},=(1-\mathrm{d}) 2 \cdot \mathrm{i}_{\mathrm{L} 1} / \mathrm{d}$ since that MOSFET is active during $(1-\mathrm{d}) \cdot \mathrm{T}$ seconds. Based on those analyses, the equivalent circuit of the closed-loop Zeta converter is presented in Figure 3 . In such a circuit the inductor $\mathrm{L} 1$ is replaced by a current source since $\mathrm{i}_{\mathrm{L} 1}$ is defined by the SMC according to (9), inductor L2 is also replaced by a current source since $\mathrm{i}_{\mathrm{L} 2}$ must fulfill the stable operation condition defined in (5). Moreover, the MOSFETs M1 and M2 are also represented by current sources with values equal to the average currents of those devices.

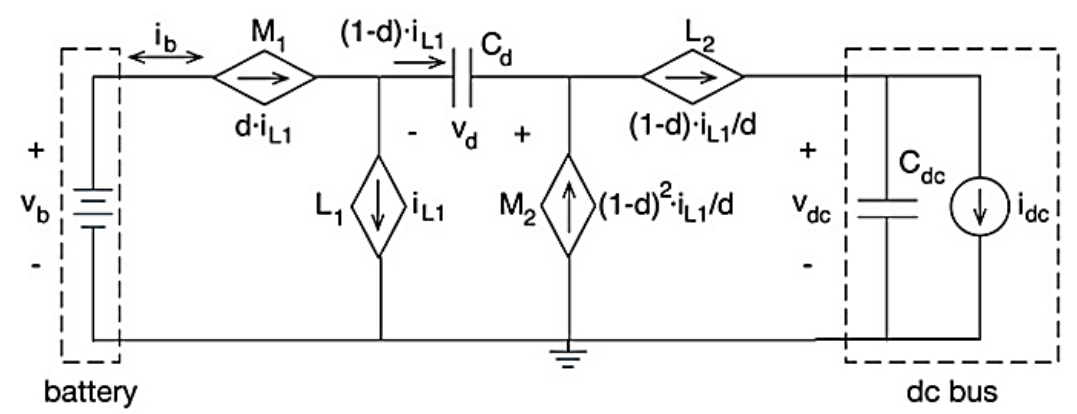

Figure 3. Closed loop equivalent circuit

Taking into account that the SMC operates within the surface, i.e., $\Psi=0$, the closed-loop L1 current imposed by the controller is:

$$
i_{L 1}=-\frac{X \cdot\left(v_{R}-v_{d c}\right)+Y \cdot \int\left(v_{R}-v_{d c}\right) d t}{Z}
$$

Applying the Laplace transformation to (22), the Laplace representation $\mathrm{I}_{\mathrm{L} 1}$ of the closed-loop current in L1 is given in (23), where $V_{R}$ and $V_{d c}$ are the Laplace representations of $v_{R}$ and $v_{d c}$, respectively. 


$$
I_{L 1}=-\frac{X \cdot s+Y}{Z \cdot s} \cdot\left(V_{R}-V_{d c}\right)
$$

From the closed-loop equivalent circuit depicted in Figure 3, the closed-loop bus voltage is defined by the controlled current in L2, i.e. (1-d) $\mathrm{i}_{\mathrm{Ll}} / \mathrm{d}$. Therefore, the differential equation modeling $\mathrm{v}_{\mathrm{dc}}$, given in (4), becomes:

$$
\frac{\mathrm{d} \mathrm{v}_{\mathrm{dc}}}{\mathrm{dt}}=\frac{1}{\mathrm{C}_{\mathrm{dc}}} \cdot\left(\frac{1-\mathrm{d}}{\mathrm{d}} \cdot \mathrm{i}_{\mathrm{L} 1}-\mathrm{i}_{\mathrm{dc}}\right)
$$

Applying the Laplace transformation to (24) and replacing the value of $\mathrm{I}_{\mathrm{L}}$ given in (23) leads to the Laplace expression for the bus voltage reported in (25). In such an expression $I_{d c}$ is the Laplace representation of the bus current $i_{\mathrm{dc}}$.

$$
V_{d c}=\frac{-\frac{1-d}{d \cdot Z} \cdot \frac{X \cdot s+Y}{s} \cdot V_{R}-I_{d c}}{C_{d c} \cdot s-\frac{1-d}{d \cdot Z} \cdot \frac{X \cdot s+Y}{s}}
$$

The (25) describes the dynamic closed-loop behavior of the bus voltage in response to changes on the reference value $v_{R}$ and bus current perturbations $I_{d c}$. However, as it was discussed before, the reference value is constant, hence there is not dynamic changes on $\mathrm{v}_{\mathrm{R}}$. Moreover, (25) depends on the duty cycle, which is affected by changes on both the bus voltage and battery voltage. Therefore, this paper uses an adaptive value of $\mathrm{Z}$ to isolate the behavior of $\mathrm{v}_{\mathrm{dc}}$ from the duty cycle. Such an adaptive value is calculated in real-time using (26), which compensates the duty cycle changes in the $v_{\mathrm{dc}}$ expression, hence the bus voltage exhibits the same behavior for any duty cycle condition. Finally, the value of $\mathrm{Z}$ is calculated from measurements of both the battery voltage and the bus voltage as it is described in (26).

$$
\mathrm{Z}=-\frac{1-\mathrm{d}}{\mathrm{d}}=-\frac{\mathrm{v}_{\mathrm{b}}}{\mathrm{v}_{\mathrm{dc}}}
$$

Then, replacing the previous $\mathrm{Z}$ value into (25), and removing the $\mathrm{v}_{\mathrm{R}}$ variable from that expression $\left(\mathrm{v}_{\mathrm{R}}\right.$ is constant), leads to the following expression for the dynamic behavior of $\mathrm{v}_{\mathrm{dc}}$ :

$$
\mathrm{V}_{\mathrm{dc}}=\frac{-\mathrm{s}}{\mathrm{C}_{\mathrm{dc}} \cdot \mathrm{s}^{2}+\mathrm{X} \cdot \mathrm{s}+\mathrm{Y}} \cdot \mathrm{I}_{\mathrm{dc}}
$$

The (27) describes the bus voltage dynamics for changes on the bus current, which could be caused by changes on the sources production, changes on the loads consumption, or both events at the same time. In any case, those changes are aggregated as changes on the bus current $I_{d c}$. The fastest change possible in $I_{d c}$ corresponds to a step current perturbation with an arbitrary amplitude $\left|\mathrm{I}_{\mathrm{dc}}\right|$, i.e., $\mathrm{I}_{\mathrm{dc}}=\frac{\left|\mathrm{I}_{\mathrm{dc}}\right|}{\mathrm{s}}$. Replacing such a current perturbation into (27) leads to (28), which describes the bus voltage waveform caused by the fastest current perturbation possible in the DC bus with an amplitude equal to the scalar value $\left|I_{d c}\right|$. Such an amplitude depends on the characteristics of both the sources and loads, e.g., maximum power and current, current slew-rate, among others.

$$
\mathrm{V}_{\mathrm{dc}}=\frac{-\left|\mathrm{I}_{\mathrm{dc}}\right|}{\mathrm{C}_{\mathrm{dc}} \cdot \mathrm{s}^{2}+\mathrm{X} \cdot \mathrm{s}+\mathrm{Y}} \quad \text { for } \quad \mathrm{I}_{\mathrm{dc}}=\frac{\left|\mathrm{I}_{\mathrm{dc}}\right|}{\mathrm{s}}
$$

The poles of transfer function (28) are given in (29).

$$
\mathrm{V}_{\mathrm{dc}}=\frac{-\frac{\left|\mathrm{I}_{\mathrm{dc}}\right|}{\mathrm{C}_{\mathrm{dc}}}}{\left(\mathrm{s}+\mathrm{P}_{1}\right) \cdot\left(\mathrm{s}+\mathrm{P}_{2}\right)} \quad \text { where } \quad \mathrm{P}_{1,2}=\frac{-\mathrm{X} \pm \sqrt{\mathrm{X}^{2}-4 \cdot \mathrm{C}_{\mathrm{dc}} \cdot \mathrm{Y}}}{2 \cdot \mathrm{C}_{\mathrm{dc}}}
$$

The previous analysis considers the poles real and different, which is much more flexible than considering both poles equal. Moreover, this poles characteristic was selected to provide smaller voltage undershoots and overshoots in comparison with complex poles. Therefore, the following restriction must be fulfilled: 


$$
\mathrm{X}^{2}>4 \cdot \mathrm{C}_{\mathrm{dc}} \cdot \mathrm{Y}
$$

Applying partial fraction decomposition and the inverse Laplace transformation to (29) leads to the timedomain waveform reported in (31).

$$
v_{d c}=\frac{\left|I_{d c}\right|}{C_{d c} \cdot\left(P_{1}-P_{2}\right)} \cdot\left(e^{-P_{1} \cdot t}-e^{-P_{2} \cdot t}\right)
$$

To design the bus voltage behavior, the following performance criteria are defined: maximum bus voltage deviation $\Delta \mathrm{v}_{\mathrm{dc}}$ and settling time ts after a step current perturbation with amplitude $\left|\mathrm{I}_{\mathrm{dc}}\right|$. The first performance criterion is analyzed by deriving the time-domain waveform (31) as (32):

$$
\frac{d v_{d c}}{d t}=\frac{\left|I_{d c}\right|}{C_{d c} \cdot\left(P_{1}-P_{2}\right)} \cdot\left(-P_{1} \cdot e^{-P_{1} \cdot t_{m d}}+P_{2} \cdot e^{-P_{2} \cdot t_{m d}}\right)=0
$$

The (32) enables to calculate the time $t_{\mathrm{md}}$ in which the maximum voltage deviation occurs (33):

$$
\mathrm{t}_{\mathrm{md}}=\frac{\ln \left(\mathrm{P}_{1}\right)-\ln \left(\mathrm{P}_{2}\right)}{\mathrm{P}_{1}-\mathrm{P}_{2}}
$$

The maximum bus voltage deviation from $\mathrm{v}_{\mathrm{R}}$ occurs at $\mathrm{t}=\mathrm{t}_{\mathrm{md}}$, which must be smaller than the limit $\Delta \mathrm{v}_{\mathrm{dc}}$. Then, the mathematical representation of this performance criterion is given in (34).

$$
\left|\mathrm{v}_{\mathrm{R}}-\mathrm{v}_{\mathrm{dc}\left(\mathrm{t}_{\mathrm{md}}\right)}\right| \leq \Delta \mathrm{v}_{\mathrm{dc}}
$$

Similarly, considering a settling time limit $\varepsilon$, which typically is $\varepsilon=2 \%$, the mathematical representation of the second performance criterion is given in (35), i.e., the bus voltage after ts seconds is within the $\varepsilon$ band.

$$
\left|\mathrm{v}_{\mathrm{R}}-\mathrm{v}_{\mathrm{dc}\left(\mathrm{t}_{\mathrm{s}}\right)}\right| \leq \varepsilon \cdot \Delta \mathrm{v}_{\mathrm{dc}}
$$

Finally, an optimization algorithm is used to find both $\mathrm{X}$ and $\mathrm{Y}$ parameters adopting inequalities (34) and (35) as objective functions, which will provide $\mathrm{X}$ and $\mathrm{Y}$ values that guarantee both performance criteria.

\section{RESULTS AND DISCUSSION}

\subsection{SMC implementation and performance evaluation}

The implementation scheme of the proposed SMC is presented in Figure 4, where the switching function $\Psi$ is calculated according to (9). Moreover, the value of $\mathrm{Z}$ is calculated in real-time according to (26). Finally, the control law defined in (15) is implemented using an hysteresis comparator, which is a common solution for sliding-mode controllers acting on DC/DC converters [3], [4] the hysteresis comparator defines an hysteresis band $\mathrm{H}$ around the sliding surface $\Psi=0$, which avoids an infinite switching frequency that could destroy the MOSFETs. Therefore, the practical control law, implemented with the circuit depicted in Figure 4, is reported in (36). The implementation of the hysteresis comparator is made using two traditional comparators and a set-reset flip-flop, which stores the present value of $\mathrm{u}$ and generates the complementary signal $\overline{\mathrm{u}}$. Then, the outputs of the flip-flop are connected to the MOSFETs M1 and M2 of Figure 1.

$$
u=\left\{\begin{array}{l}
1 \text { if } \Psi>\frac{\mathrm{H}}{2} \\
0 \text { if } \Psi<-\frac{\mathrm{H}}{2}
\end{array}\right.
$$

To illustrate the performance of the proposed solution, the following parameters are defined: $\mathrm{L} 1=\mathrm{L} 2=330 \mathrm{uH}, \mathrm{Cd}=\mathrm{Cdc}=22 \mathrm{uF}, \mathrm{C}_{\mathrm{dc}}=22 \mathrm{mF}, \mathrm{v}_{\mathrm{b}}=12.8 \mathrm{~V}$. Moreover, the performance criteria for a step current perturbation in the bus $\left|\mathrm{I}_{\mathrm{dc}}\right|=0.5 \mathrm{~A}$ are a maximum voltage deviation $\Delta \mathrm{vdc}=0.5 \mathrm{~V}$ and a maximum settling time ts $=12 \mathrm{~ms}$ for $\varepsilon=2 \%$. Applying the design procedure described in the previous section, using Matlab, the $\mathrm{X}$ and $\mathrm{Y}$ values fulfilling both (34) and (35) restrictions are obtained as $\mathrm{X}=0.98$ and $\mathrm{Y}=3.21 \mathrm{x} 102$. Those values and $\left|\mathrm{I}_{\mathrm{dc}}\right|=0.5 \mathrm{~A}$ were used to simulate the dynamic behavior of the bus voltage using (28), which 
provides the theoretical time-response of the bus voltage for the step-like current perturbation on the DC bus applied at $2 \mathrm{~ms}$ with an amplitude equal to 0.5 as shown in Figure 5. This simulation confirms the correct calculation of both $\mathrm{X}$ and $\mathrm{Y}$ since the maximum bus voltage perturbation is below $\Delta \mathrm{v}_{\mathrm{dc}}=0.5 \mathrm{~V}$ and the settling time is equal to $12 \mathrm{~ms}$ (from $2 \mathrm{~ms}$ to $14 \mathrm{~ms}$ ). Therefore, the design procedure of the SMC parameters, proposed in section 2.3 , is correct.

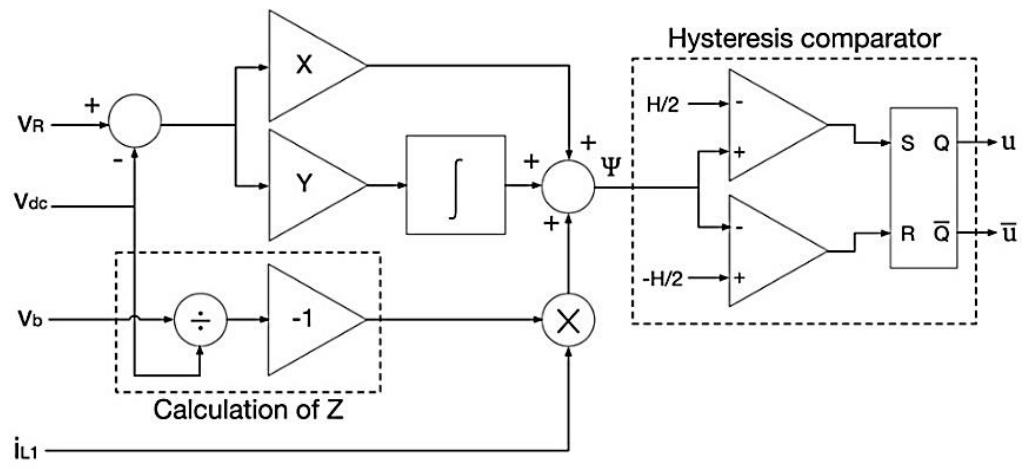

Figure 4. Implementation scheme of the proposed SMC
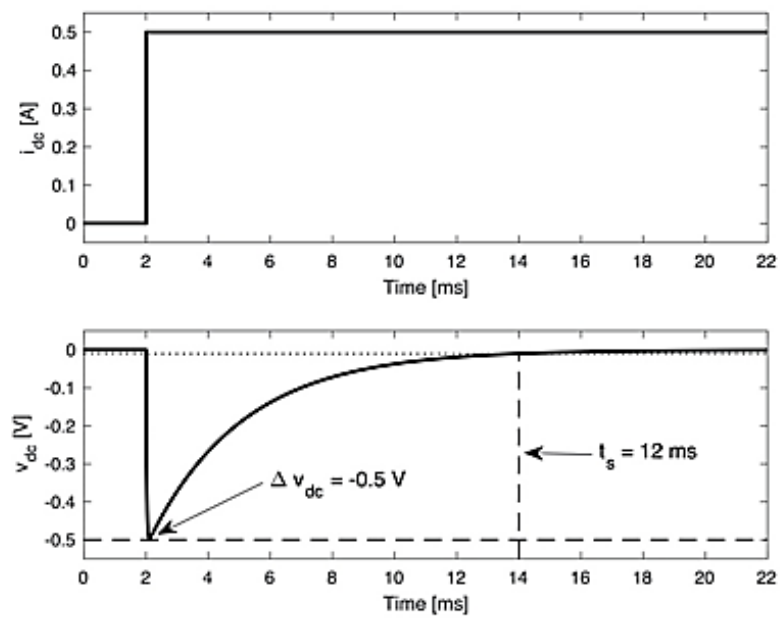

Figure 5. Theoretical time-response of the bus voltage for a 0.5 A step current perturbation

The previous $\mathrm{X}$ and $\mathrm{Y}$ values were used to parameterize the SMC circuit shown in Figure 4, which controls the battery charger depicted in Figure 1. Those circuits were implemented in the power electronics simulator PSIM, which reproduces the MOSFETs activation and the switching operation of the circuit, hence it provides a realistic evaluation of the proposed solution. Figure 6 presents a first simulation of the battery charger under the SMC regulation, which considers $\mathrm{v}_{\mathrm{b}}=12.8 \mathrm{~V}$ and a desired microgrid bus voltage $\mathrm{V}_{\mathrm{R}}=12 \mathrm{~V}$; in addition, the hysteresis comparator was configured with $\mathrm{H}=0.55$ to limit the switching frequency to $120 \mathrm{kHz}$. The simulation considers step current transients of $0.5 \mathrm{~A}$ in the DC bus, both positive (battery discharge) and negative (battery charge), those producing bus voltage deviations constrained into $0.5 \mathrm{~V}$ and with settling times equal to $12 \mathrm{~ms}$, which confirm the correct operation of the SMC. Moreover, the simulation also put into evidence the stability of the SMC: the duty cycle $d$ is not saturated; hence the equivalent control condition is fulfilled; and the switching function $\Psi$ is always constrained into the hysteresis band [-H/2, H/2], hence the system is always operating into the sliding-surface, i.e., $\Psi=0$ and $\frac{\mathrm{d} \Psi}{\mathrm{dt}}=0$. Figure 7 shows a zoom of the previous circuital simulation at the instant in which the first current transient occurs $(9.9 \mathrm{~ms}<\mathrm{t}<10.3 \mathrm{~ms})$. This figure enables to observe the detailed waveform of the switching function, which even under fast perturbations never leaves the hysteresis band. This condition confirms that the battery charger is always operating in closed-loop, which guarantee the stability of the DC bus. 
The closed-loop dynamics of the battery charger, reported in (27) and (28), are independent of both the reference and bus voltage, hence the battery charger must exhibit the same bus voltage behavior for any reference condition. Therefore, a second set of simulations were performed considering $\mathrm{V}_{\mathrm{R}}=8 \mathrm{~V}, 12 \mathrm{~V}$ and $16 \mathrm{~V}$ under the action of a step-up current perturbation of $0.5 \mathrm{~A}$ in the DC bus. The simulation results are presented in Figure 8, which shows a very similar performance of the bus voltage under three different conditions: $\mathrm{V}_{\mathrm{R}}=8 \mathrm{~V}$ forces the battery charger to operate in buck mode (since the battery voltage is $\left.\mathrm{v}_{\mathrm{b}}=12.8 \mathrm{~V}\right), \mathrm{v}_{\mathrm{R}}=12 \mathrm{~V}$ forces the battery charger to operate in near buck-boost mode, and $\mathrm{v}_{\mathrm{R}}=16 \mathrm{~V}$ forces the battery charger to operate in boost mode.

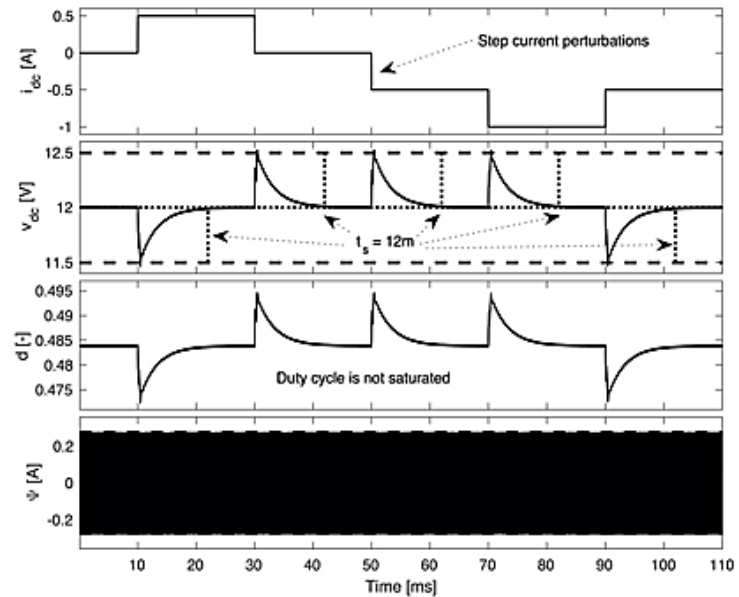

Figure 6. Circuital simulation with $\mathrm{v}_{\mathrm{R}}=12 \mathrm{~V}$ and $\mathrm{v}_{\mathrm{b}}=12.8 \mathrm{~V}$

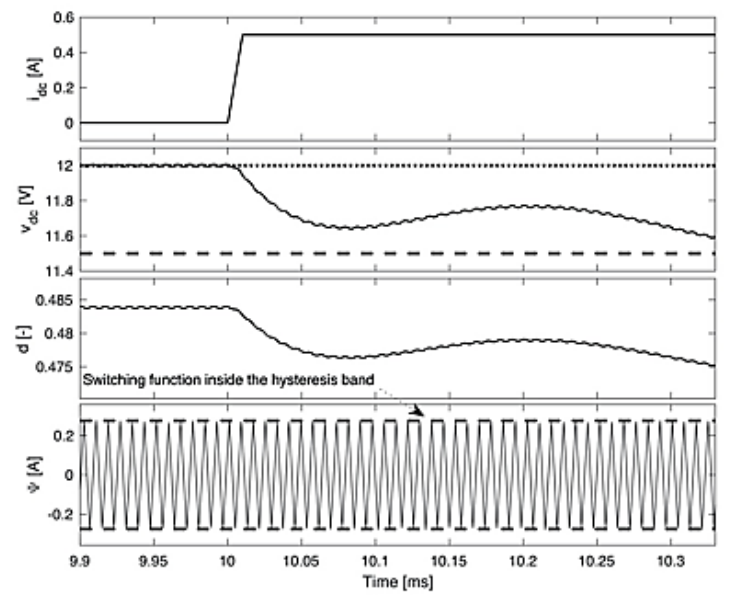

Figure 7. Zoom of the circuital simulation with $\mathrm{v}_{\mathrm{R}}=12 \mathrm{~V}$ and $\mathrm{v}_{\mathrm{b}}=12.8 \mathrm{~V}$
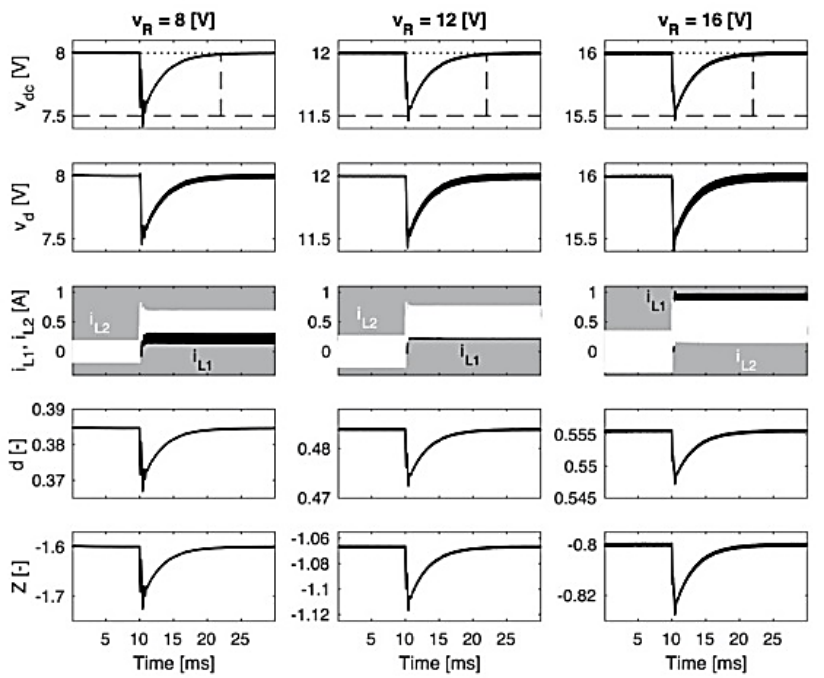

Figure 8. Circuital simulation with $\mathrm{v}_{\mathrm{b}}=12.8 \mathrm{~V}$ and $\mathrm{v}_{\mathrm{R}}=8 \mathrm{~V}, 12 \mathrm{~V}$ and $16 \mathrm{~V}$

In addition, the differential $\mathrm{v}_{\mathrm{d}}$ voltage is also presented, which has the same behavior for the three operation conditions; moreover, $\mathrm{v}_{\mathrm{d}}$ is equal to $\mathrm{v}_{\mathrm{dc}}$ as it is predicted by the stable operation condition given in (7). Similarly, the inductors currents are also presented, which fulfill the stable operation condition reported in (5) for all the output voltage conditions. The duty cycle of the converter is also presented, where no saturation is observed despite de output voltage. Finally, the $\mathrm{Z}$ value is reported for the three operation conditions, which put into evidence the adaptability of the proposed SMC to changes on the bus and reference voltages. 
In conclusion, the detailed circuital simulations presented in this section show the correctness of the design procedure for $\mathrm{X}$ and $\mathrm{Y}$ parameters, the adaptability of the $\mathrm{Z}$ parameter, the general stability of the proposed SMC, and the ability of the battery charger to operate in a wide range of conditions: charge and discharge of the battery at any voltage relation between the battery and the DC bus (boost, buck, and buckboost conditions). Therefore, the proposed battery charger and SMC provide a general solution for battery chargers with global stability and satisfactory performance.

\subsection{Experimental validation}

The proposed battery charger and SMC were implemented using a proof-of-concept circuit to provide an experimental validation of the solution feasibility. The experimental platform, depicted in Figure 9 was constructed following the circuital schemes of the Zeta converter and SMC given in Figure 1 and Figure 4, respectively. This experimental platform is formed by a lead-acid battery with nominal operation voltage equal to $12.8 \mathrm{~V}$, connected to the Zeta converter, which performs both charge and discharge operations. Moreover, the microgrid bus is emulated using an electronic source/load, which is able to consume and provide current, hence it could emulate all the operation conditions of the bus: sources producing more power than the load demand (bus providing current), sources producing less power than the load demand (bus consuming current), and sources producing the same power than the load demand (net bus current equal to zero).

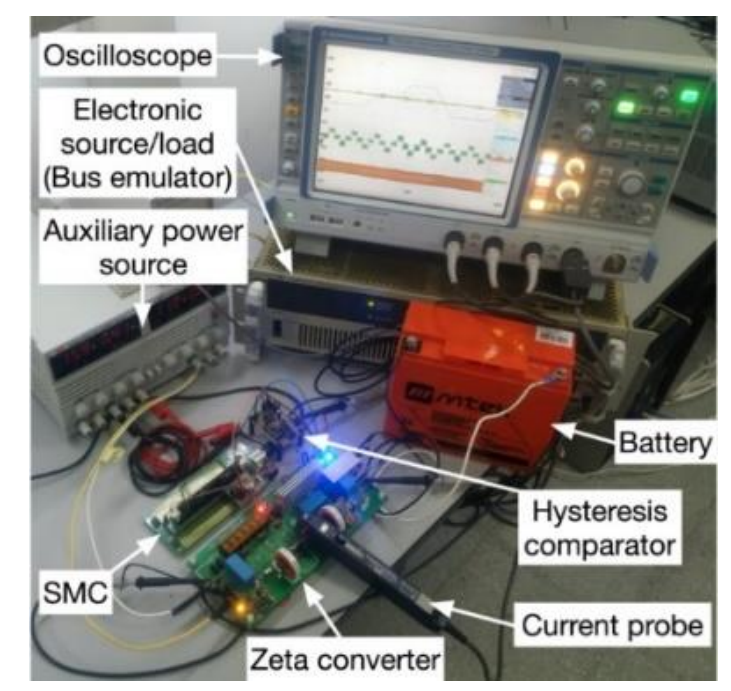

Figure 9. Experimental platform for testing both the battery charger and SMC

The SMC was implemented using a digital processor and an analog hysteresis comparator. The digital processor (F28335 controlCARD) calculates the switching function $\Psi$ from the measurements digitalized using the internal analog-to-digital converter of the controlCARD. The hysteresis comparator (TS555) generates the control signals $\mathrm{u}$ and $\overline{\mathrm{u}}$ using analog values of $\mathrm{H}$ and $\Psi$, which are produced using the digital-to-analog converter MCP4822. Figure 9 also shows the current probe used to visualize the bus current into the oscilloscope, and the auxiliary power source used to power the controlCARD and the TS555. Finally, the circuit was configured with $\mathrm{H}=5$ to limit the switching frequency to $60 \mathrm{kHz}$, which is the highest frequency achievable by the prototype.

The first experiment was designed to validate the simulation reported in Figure 6 . The battery charger is controlled at $\mathrm{v}_{\mathrm{R}}=12 \mathrm{~V}$ under step current transients of $0.5 \mathrm{~A}$ and with the battery voltage $\mathrm{v}_{\mathrm{b}}=12.8 \mathrm{~V}$. The experimental results are presented in Figure 10, where the battery voltage is presented in the yellow trace, the bus voltage in blue trace, the bus current in green trace and the switching function in orange trace. The experiment shows that the DC bus current exhibits step transients of $0.5 \mathrm{~A}$ to reach positive (discharge), negative (charge) and zero (stand-by) current values. Under those conditions the experimental bus voltage is satisfactory regulated within $0.5 \mathrm{~V}$ around $\mathrm{v}_{\mathrm{R}}=12 \mathrm{~V}$ and with settling times equal to $12 \mathrm{~ms}$, which confirms the correct operation of the SMC. Moreover, the experiment shows that the switching function $\Psi$ is always constrained into the hysteresis band [-2.5, 2.5], hence the system is always operating into the sliding-surface. Therefore, this experiment confirms the validity of the SMC analyses and design procedure. 
A second experiment was conducted to validate the isolation of the SMC design from the bus voltage value, and at the same time, to validate the simulations presented in Figure 8 . The results of this second experiment are presented in Figure 11, where the color waveforms are the same ones described for the first experiment. This experiment forces the operation of the battery charger in three operation conditions: $\mathrm{v}_{\mathrm{R}}=8 \mathrm{~V}, \mathrm{v}_{\mathrm{R}}=12.8 \mathrm{~V}$, and $\mathrm{v}_{\mathrm{R}}=18 \mathrm{~V}$. The first one $(8 \mathrm{~V})$ sets the experimental prototype in buck mode (voltage conversion ratio lower than one), imposing step current transients of $0.5 \mathrm{~A}$ for charge, discharge, and standby conditions. The second reference value $(12.8 \mathrm{~V})$ sets the prototype in buck/boost mode (voltage conversion ratio equal to one) for the same current transients and power flows. Finally, the third reference value $(18 \mathrm{~V})$ sets the prototype in boost mode (voltage conversion ratio higher than one), also imposing the same current transients and power flows. The bus voltage waveform shows a stable behavior for all the reference voltages and charge/discharge conditions, and it is observed that the SMC always operates into the sliding-surface defined by the hysteresis band. Therefore, this experiment confirms the SMC stability for any operation condition. Moreover, this experiment also verifies the flexibility of the proposed battery charger since this solution could be used to interface batteries and microgrids exhibiting any voltage relation. Finally, the previous experiments validate the SMC stability, the design procedure for X and Y parameters, and the correctness of the strategy proposed to adapt the $\mathrm{Z}$ parameter to any operation condition: battery charge, discharge or stand-by; and to voltage conversion ratios lower, equal, or higher than one.

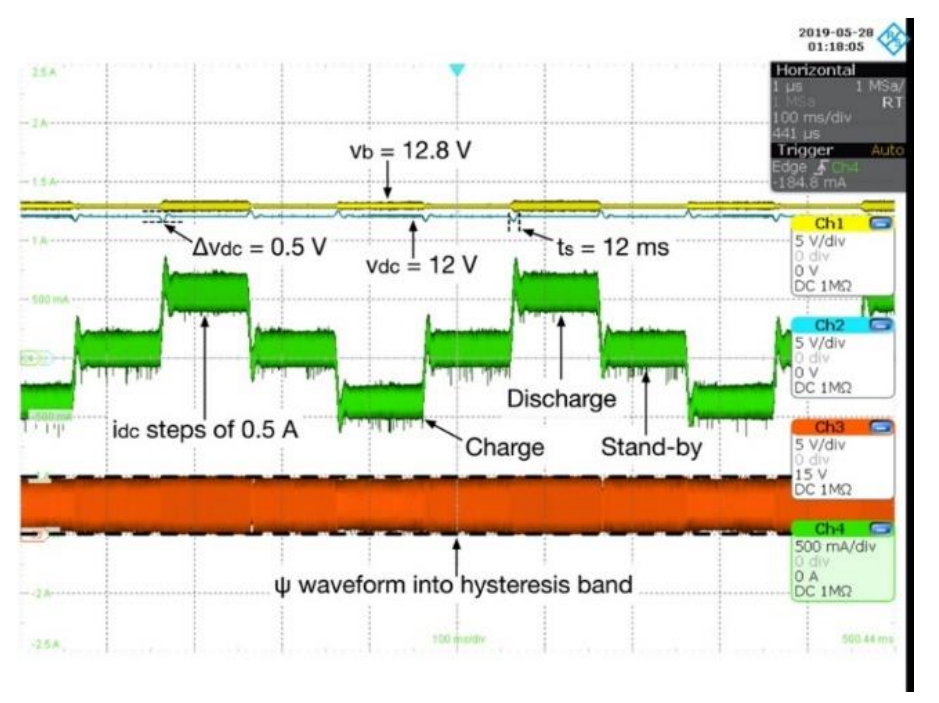

Figure 10. Bus regulation at $\mathrm{v}_{\mathrm{R}}=12 \mathrm{~V}$ under current transients of $0.5 \mathrm{~A}$ and $\mathrm{v}_{\mathrm{b}}=12.8 \mathrm{~V}$

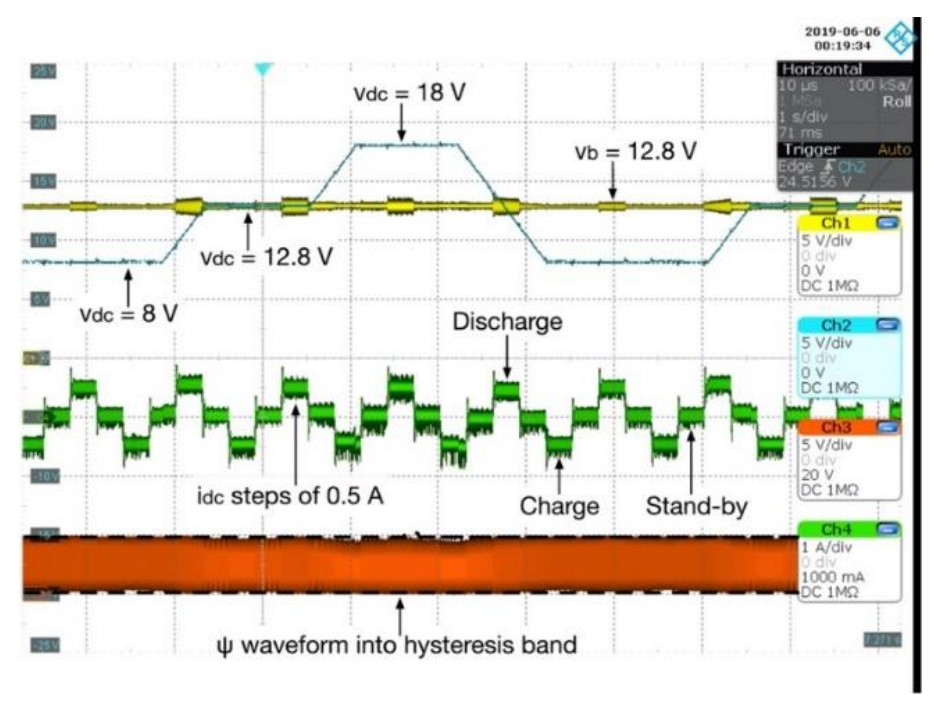

Figure 11. Bus regulation at $\mathrm{v}_{\mathrm{R}}=8 \mathrm{~V}, \mathrm{v}_{\mathrm{R}}=12.8 \mathrm{~V}$, and $\mathrm{v}_{\mathrm{R}}=18 \mathrm{~V}$ 


\section{CONCLUSION}

A battery charger, based on the Zeta DC/DC converter and a sliding-mode controller, has been presented. The main characteristic of this solution is to require a single inductor measurement, which provides a cheaper implementation in comparison with controllers based on the measurement of both inductors current. Moreover, the use of the Zeta converter enables to interface batteries and DC buses with voltage conversion ratios lower, equal, or higher than one, hence this solution could replace multiple battery chargers based on buck, boost, or back-boost topologies. The controller was designed to be isolated from the bus voltage value; hence the battery charger could operate at any bus voltage (lower, equal, or higher than the battery voltage) without requiring any adjustment, which ensures global stability. This characteristic was analytically demonstrated using the sliding-mode proofs, and the proposed design procedure for the controller parameters was also verified. Similarly, the performance of the battery charger was satisfactorily verified using detailed circuital simulations, in which both the maximum bus voltage deviation and settling time achieved were the designed ones. This correct behavior was experimentally validated using a proof-ofconcept prototype, which also exhibits the correct bus voltage deviation and settling time at multiple bus voltage conditions. Therefore, this solution could be the starting point of a commercial battery charger providing flexibility in terms of voltage conversion ratio, hence enabling the user to replace the battery of a microgrid without requiring any particular battery voltage.

The main drawback of this solution concerns the fast effect of the current transients into the DC bus voltage, which are impossible to avoid since the capacitor current is defined by those transients. This effect could be reduced by including the bus current into the sliding-mode controller, but this will need an additional current sensor, which is the opposite of the solution objective. Another solution could be to estimate some inductor current from the DC bus current and other variables, which will require a single current sensor. This possible improvement is an interesting subject for a future work. Another drawback concerns the common connection between the battery and the microgrid, which could lead to ground current loops when ground isolators are not used. Those ground current loops could produce damages in the control circuits, thus leaving the system unstable. This potential problem is impossible to prevent using the Zeta topology; but using isolated topologies, such as the dual-active-bridge converter, could be a solution to avoid those ground current loops. This possible improvement is also a subject for a future work.

\section{ACKNOWLEDGEMENTS}

The authors thank the Instituto Tecnológico Metropolitano for the Open access fee payment under the project P21101 'Fortalecimiento Y Consolidación Del Grupo Automática, Electrónica Y Ciencias Computacionales Para Responder A Las Necesidades De Las Industrias 4.0'.

\section{REFERENCES}

[1] M. Shafiee-Rad, M. S. Sadabadi, Q. Shafiee, and M. R. Jahed-Motlagh, "Robust decentralized voltage control for uncertain DC microgrids," International Journal of Electrical Power \& Energy Systems, vol. 125, Feb. 2021, Art. no. 106468, doi: 10.1016/j.ijepes.2020.106468.

[2] T. Dragicevic, J. M. Guerrero, J. C. Vasquez, and D. Skrlec, "Supervisory control of an adaptive-droop regulated DC microgrid with battery management capability," IEEE Transactions on Power Electronics, vol. 29, no. 2, pp. 695-706, Feb. 2014, doi: 10.1109/TPEL.2013.2257857.

[3] S. Serna-Garcés, D. Gonzalez Montoya, and C. Ramos-Paja, "Sliding-mode control of a charger/discharger DC/DC converter for DC-bus regulation in renewable power systems," Energies, vol. 9, no. 4, Mar. 2016, Art. no. 245, doi: 10.3390/en9040245.

[4] J. D. Bastidas-Rodríguez, D. González, S. Acevedo, and J. Peláez-Restrepo, "Design and control of a buck-boost chargerdischarger for DC-bus regulation in microgrids," Energies, vol. 10, no. 11, Art. no. 1847, Nov. 2017, doi: 10.3390/en10111847.

[5] P. K. Gayen, P. Roy Chowdhury, and P. K. Dhara, "An improved dynamic performance of bidirectional SEPIC-Zeta converter based battery energy storage system using adaptive sliding mode control technique," Electric Power Systems Research, vol. 160, pp. 348-361, Jul. 2018, doi: 10.1016/j.epsr.2018.03.016.

[6] E. Sunarno, I. Sudiharto, S. D. Nugraha, F. D. Murdianto, Suryono, and O. A. Qudsi, "Design and implementation bidirectional SEPIC/ZETA converter using fuzzy logic controller in DC microgrid application," Journal of Physics: Conference Series, vol. 1367, Nov. 2019, Art. no. 012058, doi: 10.1088/1742-6596/1367/1/012058.

[7] S. I. Serna-Garc, D. G. Lez Montoya, and C. A. S. Ramos-Paja, "Control of a charger/discharger DC/DC converter with improved disturbance rejection for bus regulation," Energies, vol. 11, no. 3, 2018, doi: 10.3390/en11030594.

[8] Y. Wei, Q. Luo, X. Du, N. Altin, A. Nasiri, and J. M. Alonso, "A dual half-bridge LLC resonant converter with magnetic control for battery charger application," IEEE Transactions on Power Electronics, vol. 35, no. 2, pp. 2196-2207, Feb. 2020, doi: 10.1109/TPEL.2019.2922991.

[9] A. N. Hussain, A. J. Ali, and F. S. Ahmed, "Power quality improvement based on hybrid coordinated design of renewable energy sources for DC link channel DSTATCOM," International Journal of Electrical and Computer Engineering (IJECE), vol. 10, no. 5, pp. 5108-5122, Oct. 2020, doi: 10.11591/ijece.v10i5.pp5108-5122.

[10] D. Chowdhury, M. S. Miah, M. F. Hossain, and U. Sarker, "Implementation of a grid-tied emergency back-up power supply for medium and low power application," International Journal of Electrical and Computer Engineering (IJECE), vol. 10, no. 6, pp. 6233-6243, Dec. 2020, doi: 10.11591/ijece.v10i6.pp6233-6243.

[11] R. Thumma, V. V. S. Kumar Bhajana, and P. kumar Aylapogu, "Design and simulation of a new ZVT Bi-directional DC-DC 
converter for electric vehicles," Indonesian Journal of Electrical Engineering and Computer Science (IJEECS), vol. 7, no. 1, pp. 75-83, Jul. 2017, doi: 10.11591/ijeecs.v7.i1.pp75-83.

[12] C. E. Quintero, S. A. Pérez, J. P. V. Ceballos, D. Daniel, and S. S. Garcés, "Desain dan kontrol digital dari konverter boost interlaced untuk sistem pengisian/pengosongan baterai," (in Spanish), TecnoLógicas, vol. 24, no. 50, pp. 4-21, Jan. 2021, doi: $10.22430 / 22565337.1556$.

[13] K. El Khadiri, H. Akhmal, and H. Qjidaa, "Li-ion battery charging with a buck-boost DC-DC converter for a portable device power management," Journal of Low Power Electronics, vol. 13, no. 2, pp. 263-270, Jun. 2017, doi: 10.1166/jolpe.2017.1479.

[14] I. Alhamrouni, M. K. Rahmat, F. A. Ismail, M. Salem, A. Jusoh, and T. Sutikno, "Design and development of SEPIC DC-DC boost converter for photovoltaic application," International Journal of Power Electronics and Drive Systems (IJPEDS), vol. 10, no. 1, pp. 406-413, Mar. 2019, doi: 10.11591/ijpeds.v10.i1.pp406-413.

[15] A. Goudarzian and A. Khosravi, "Application of DC/DC Ćuk converter as a soft starter for battery chargers based on double-loop control strategy," International Journal of Circuit Theory and Applications, vol. 47, no. 5, pp. 753-781, 2019, doi: $10.1002 /$ cta.2615

[16] S. I. Khather and M. A. Ibrahim, "Modeling and simulation of SEPIC controlled converter using PID controller," International Journal of Power Electronics and Drive Systems (IJPEDS), vol. 11, no. 2, pp. 833-843, Jun. 2020, doi: 10.11591/ijpeds.v11.i2.pp833-843.

[17] H. Fakham, D. Lu, and B. Francois, "Power control design of a battery charger in a hybrid active PV generator for load-following applications," IEEE Transactions on Industrial Electronics, vol. 58, no. 1, pp. 85-94, Jan. 2011, doi: 10.1109/TIE.2010.2062475.

[18] A. K. Singh and M. K. Pathak, "Single-stage ZETA-SEPIC-based multifunctional integrated converter for plug-in electric vehicles," IET Electrical Systems in Transportation, vol. 8, no. 2, pp. 101-111, Jun. 2018, doi: 10.1049/iet-est.2017.0063.

[19] A. J. Morelo, S. C. Trujillo, and F. E. Hoyos, "Simulation, bifurcation, and stability analysis of a SEPIC converter controlled with ZAD," International Journal of Electrical and Computer Engineering (IJECE), vol. 10, no. 1, pp. 728-737, Feb. 2020, doi: 10.11591/ijece.v10i1.pp728-737.

[20] M. Venmathi and R. Ramaprabha, "Investigation on fuzzy logic based centralized control in four-port SEPIC/ZETA bidirectional converter for photovoltaic applications," Advances in Electrical and Computer Engineering, vol. 16, no. 1, pp. 53-60, 2016, doi: 10.4316/AECE.2016.01008.

[21] F. Altaf, B. Egardt, and L. J. Mardh, "Load management of modular battery using model predictive control: thermal and state-ofcharge balancing," IEEE Transactions on Control Systems Technology, vol. 25, no. 1, pp. 47-62, Jan. 2017, doi: 10.1109/TCST.2016.2547980.

[22] A. Goudarzian, A. Khosravi, and H. A. Raeisi, "A new approach in design of sliding-mode voltage-controller for a SEPIC," International Journal of Dynamics and Control, vol. 9, no. 3, pp. 1197-1209, Sep. 2021, doi: 10.1007/s40435-020-00741-9.

[23] E. E. Henao-Bravo, A. J. Saavedra-Montes, C. A. Ramos-Paja, J. D. Bastidas-Rodriguez, and D. Gonzalez-Montoya, "Charging/discharging system based on zeta/sepic converter and a sliding mode controller for dc bus voltage regulation," IET Power Electronics, vol. 13, no. 8, pp. 1514-1527, Jun. 2020, doi: 10.1049/iet-pel.2019.0746.

[24] J. Saeed, M. Niakinezhad, N. Fernando, and L. Wang, "Model predictive control of an electric vehicle motor drive integrated battery charger," in 2019 IEEE 13th International Conference on Compatibility, Power Electronics and Power Engineering (CPE-POWERENG), Apr. 2019, pp. 1-6, doi: 10.1109/CPE.2019.8862423.

[25] H. Zhong, J. Li, and Y.-X. Wang, "A bus-based battery equalization via modified isolated cuk converter governed by adaptive control," in 2019 Chinese Automation Congress (CAC), Nov. 2019, pp. 2824-2828, doi: 10.1109/CAC48633.2019.8996984.

[26] J. L. Mathieu and J. A. Taylor, "Controlling nonlinear batteries for power systems: Trading off performance and battery life," in 2016 Power Systems Computation Conference (PSCC), Jun. 2016, pp. 1-7, doi: 10.1109/PSCC.2016.7540856.

[27] G.-C. Hsieh, L.-R. Chen, and K.-S. Huang, "Fuzzy-controlled active state-of-charge controller for fasting the charging behavior of Li-ion battery," in IECON'99. Conference Proceedings. 25th Annual Conference of the IEEE Industrial Electronics Society (Cat. No.99CH37029), 1999, vol. 1, pp. 400-405, doi: 10.1109/IECON.1999.822231.

[28] Dimna Denny C and Shahin M, "Analysis of bidirectional SEPIC/Zeta converter with coupled inductor," in 2015 International Conference on Technological Advancements in Power and Energy (TAP Energy), Jun. 2015, pp. 103-108, doi: 10.1109/TAPENERGY.2015.7229600

[29] N. Siddharthan and B. Balasubramanian, "Performance evaluation of SEPIC, Luo and ZETA converter," International Journal of Power Electronics and Drive Systems (IJPEDS), vol. 10, no. 1, pp. 374-380, Mar. 2019, doi: 10.11591/ijpeds.v10.i1.pp374-380.

[30] R. Palanisamy, K. Vijayakumar, V. Venkatachalam, R. M. Narayanan, D. Saravanakumar, and K. Saravanan, "Simulation of various DC-DC converters for photovoltaic system," International Journal of Electrical and Computer Engineering (IJECE), vol. 9, no. 2, pp. 917-925, Apr. 2019, doi: 10.11591/ijece.v9i2.pp917-925.

[31] R. A. Aprilianto, S. Subiyanto, and T. Sutikno, "Modified SEPIC converter performance for grid-connected PV systems under various conditions," TELKOMNIKA (Telecommunication Computing Electronics and Control), vol. 16, no. 6, pp. 2943-2953, Dec. 2018, doi: 10.12928/telkomnika.v16i6.10148.

[32] S. A. Gorji, H. G. Sahebi, M. Ektesabi, and A. B. Rad, "Topologies and control schemes of bidirectional DC-DC power converters: an overview," IEEE Access, vol. 7, pp. 117997-118019, 2019, doi: 10.1109/ACCESS.2019.2937239.

[33] N. Sujitha and S. Krithiga, "RES based EV battery charging system: A review," Renewable and Sustainable Energy Reviews, vol. 75, pp. 978-988, Aug. 2017, doi: 10.1016/j.rser.2016.11.078.

[34] A. Kloenne and T. Sigle, "Bidirectional ZETA/SEPIC converter as battery charging system with high transfer ratio," in 2017 19th European Conference on Power Electronics and Applications (EPE'17 ECCE Europe), Sep. 2017, pp. 1-7, doi: 10.23919/EPE17ECCEEurope.2017.8099321.

[35] H. Sira-Ramirez, "Sliding motions in bilinear switched networks," IEEE Transactions on Circuits and Systems, vol. 34, no. 8, pp. 919-933, Aug. 1987, doi: 10.1109/TCS.1987.1086242.

[36] R. W. Erickson and D. Maksimovic, Fundamentals of Power Electronics, 2nd ed. Springer, 2005.

[37] S. Serna-Garcés, D. González Montoya, and C. Ramos-Paja, "Control of a charger/discharger DC/DC converter with improved disturbance rejection for bus regulation,” Energies, vol. 11, no. 3, Art. No. 594, Mar. 2018, doi: 10.3390/en11030594. 